\title{
Moral Testimony Pessimism and the Uncertain Value of Authenticity
}

ANDREAS L. MOGENSEN

University of Oxford

\begin{abstract}
Many philosophers believe that there exist distinctive obstacles to relying on moral testimony. In this paper, I criticize previous attempts to identify these obstacles and offer a new theory. I argue that the problems associated with moral deference can't be explained in terms of the value of moral understanding, nor in terms of aretaic considerations related to subjective integration. Instead, our uneasiness with moral testimony is best explained by our attachment to an ideal of authenticity that places special demands on our moral beliefs.
\end{abstract}

\section{Introduction}

Although we can happily rely on the word of others when it comes to the geography of India or the mating habits of penguins, it seems we can't be quite so willing to accept testimony on moral questions. Consider the following example. Danielle hears about an upcoming demonstration protesting Israel's war in Gaza. Although she knows the causes of the war and knows that civilians are dying from IDF bombing, Danielle is unsure whether the war is just. She doesn't try to think through the matter for herself. Instead, she asks a reliable and trustworthy friend, who says the war is immoral. Danielle accepts her friend's claim and joins the protest. Asked by a journalist why she is demonstrating, Danielle says she knows the war is wrong because her friend told her so.

Danielle's willingness to defer to her friend in this way is likely to strike many of us as peculiar, though we might not bat an eye at her taking it on authority from the same 
friend that the Taj Mahal is in Agra or that gentoo penguins pair-bond. Reflecting on cases like this, many philosophers have come to the view that there is something distinctively problematic about moral testimony: something in the nature of morality requires that we give less weight to the word of others in settling moral questions. ${ }^{1}$ This view has been called moral testimony pessimism.

I'm going to assume in this paper that pessimism provides the best fit for our intuitions about moral testimony. ${ }^{2}$ I think pessimists have argued convincingly that this is the case. ${ }^{3}$ The key issue isn't whether our intuitions accord with pessimism, but why. Supposing there are domain-specific normative requirements that tell against relying on the word of others in ethics, what is the nature of these requirements and what are the values and ideals that ground them? These are the problems I'll be addressing. I'll try to show that existing solutions are unsatisfactory and that our uneasiness with moral testimony is best explained by our attachment to an ideal of authenticity that places special demands on our moral beliefs. Whether this ideal is ultimately defensible is a further question that I'll leave unanswered.

Here's the plan. In section 2, I'll clarify the commitments of moral testimony pessimism. There has been some confusion on this point and some spurious arguments. With this issue clarified, I'll then try to show that pessimists have so far failed to supply a plausible explanation for the existence of distinctive obstacles to relying on moral testimony. In section 3, I put forward a number of objections to the popular view that moral testimony is distinctively problematic because it fails to convey understanding. In section 4, I argue against a more recent proposal which explains the problems associated with moral

\footnotetext{
${ }^{1}$ Aiken (1962), Crisp (2014), Estlund (2008), Hare (1963), Hills (2009, 2010), Howell (2014), McGrath (2011), Nickel (2001), Wolff (1970).

${ }_{2}$ Pace Driver (2006), Groll \& Decker (2014), Lillehammer (2014), McGrath (2009), Sliwa (2012).

${ }^{3}$ I'm particularly impressed by the arguments put forward by Howell (2014) and McGrath (2011).
} 
testimony in terms of aretaic considerations related to subjective integration. I then set out my own view: that our uneasiness with moral testimony is best explained by the value we set on authenticity. In section 5, I'll explain why authenticity places special demands on our moral beliefs and outline a number of desirable qualities distinctive to my proposal, such as the ability to explain straightforwardly why aesthetic testimony shares the problematic features associated with moral testimony.

My aim is not to vindicate pessimism, but to explain why it appears plausible. While I think the ideal of authenticity explains our intuitions about moral testimony, I'm unsure that the value of authenticity stands up to critical scrutiny. There's a much larger debate to be had on this issue. I want to convince you that settling this debate is necessary to determining the value of moral testimony.

\section{Clarifying pessimism}

Since I want to explain why pessimism appears plausible to us, I'm going to start by clarifying exactly what this position involves. This is especially important as pessimism has been confused with a view about moral testimony that is much less nuanced - and much less plausible.

We can start by noting that pessimists are not in any sense straightforwardly against relying on moral testimony. Pessimists don't believe that it is always inappropriate to defer in deciding moral questions. Nor need they think that it is typically inappropriate.

Many ways of relying on others are deemed perfectly acceptable by those in the pessimist camp. For example, pessimists grant that we can allow others to persuade us via moral arguments. ${ }^{4}$ It's fine if Danielle chooses to protest the Gaza war after having been convinced by the case set out by Jeff McMahan (2014). Of course, this wouldn't involve

\footnotetext{
${ }^{4}$ Hills (2009: 122-123), Howell (2014: 389-390), Wolff (1970: 13).
} 
deferring in any meaningful sense. Danielle would come to the same view as McMahan based on the cogency of his arguments, not his authority as a moral expert.

Pessimists also think it's fine to defer on moral questions when we know that others have access to relevant facts which settle what to do in light of shared values. ${ }^{5}$ Thus, if an expert on explosives tells me I ought to cut the red wire, I can trust that she knows the right thing to do. ${ }^{6}$ This involves a relatively weak form of moral deference. Although I'm in some sense deferring on the right course of action, I merely assume the expert understands how to keep the bomb from blowing up. I know by my own lights that this is what matters morally. Sarah McGrath (2009, 2011) describes cases like this as involving impure deference.

The more problematic cases are those involving what McGrath calls pure deference. These are cases where we rely on the say-so of others to settle moral questions and this isn't simply because we think they have superior knowledge of relevant non-moral facts: we credit them with genuine moral insight. Pessimists aren't committed to the view that pure deference is always inappropriate, however. For example, pessimists typically grant that we can defer to others if we know that we're unable to resolve a difficult moral issue and reasonably expect that others can do better. ${ }^{7}$ This concession is significant, as it's plausible that these are precisely the conditions under which people ordinarily turn to others for help in deciding on the right course of action. A closely related concession allows that children and others who lack minimal moral competence should defer to others. ${ }^{8}$

These concessions may appear surprising. What we have to keep in mind is that pessimism is as much - if not more so - a view about the importance of figuring things out for ourselves. In Danielle's case, we don't simply feel that it's inappropriate for her to defer:

\footnotetext{
${ }^{5}$ Howell (2014: 391), McGrath (2011: 113-114).

${ }^{6}$ I borrow this example from Enoch (2014).

${ }^{7}$ Hills (2009: 123-124), Hopkins (2007: 613), Howell (2014: 390), Nickel (2001: 265).

${ }^{8}$ Hills (2010: 172), Howell (2014: 390).
} 
we feel that she ought to think through the matter on her own terms. Contrast this with Estelle, who is pondering the meaning of her star sign. Here, we feel not only that Estelle shouldn't consult with astrologers but also that she shouldn't try to draw up her own horoscope. Danielle's case is not like that. Pessimism is supposed to explain why we feel especially obligated in this way to draw our own moral conclusions. We might think of the recommendation to forego moral testimony as a consequence of this more foundational requirement. Assuming that ought implies can, it follows straightforwardly that the requirement lapses if we know we can't settle the issue alone. ${ }^{9}$

Pessimism is therefore not a blanket ban on moral testimony, nor even on pure deference. These nuances can be overlooked. In a recent paper, Paulina Sliwa (2012) attributes to pessimists a principle she calls No Testimony, according to which, "For a mature moral agent, there is something wrong with relying on testimony for one's moral beliefs even if one knows one's source to be reliable and trustworthy." (176) Sliwa argues against this principle, presenting a number of cases in which people come to realize that they are unable to resolve a moral dilemma and defer to others in deciding what to do. According to Sliwa, there isn't anything wrong with relying on moral testimony in these cases, so No Testimony must be false. That may be so, but it doesn't conflict with anything to which pessimists are committed. Pessimism predicts that reliance on moral testimony loses its problematic status in these cases.

Ultimately, pessimism is best understood not as a claim about the extent to which we can rely on others, but as a claim about how to explain the inappropriateness of deference in those cases where deference is inappropriate. Pessimists maintain that we can't fully capture the obstacles to relying on moral testimony by appealing to domain-general requirements on justified trust. To get the full story, we have to invoke normative considerations specific to the moral domain.

\footnotetext{
${ }^{9}$ Hopkins (2007: 613).
} 
Two important qualifications should be added to this characterisation. Firstly, we need to be careful in interpreting the claim that the norms governing moral testimony are domain-specific. Many philosophers are inclined to think that the problematic features associated with moral testimony are shared by cases of aesthetic testimony. Thus, if someone tells me Vertigo is the greatest film ever made, I expect them to have seen it. If it turns out they're just relying on the fact that Vertigo topped the Sight \& Sound Greatest Films Poll, I feel misled. ${ }^{10}$ In light of cases like this, a parallel debate has emerged about the value and status of aesthetic testimony. ${ }^{11}$ Some argue that the inappropriateness of deferring on aesthetic questions can't be captured by general epistemic requirements. ${ }^{12}$ Others dispute this. ${ }^{13}$

We shouldn't understand moral testimony pessimism as entailing that the norms which tell against relying on moral testimony must necessarily be different in kind from those that tell against relying on aesthetic testimony. Pessimists don't have to think of the special norms governing moral testimony as strictly confined to the moral domain. A unified explanation for our reluctance to accept moral and aesthetic testimony is arguably pro tanto preferable.

Here is the second important qualification that we have to take on board. Testimony per se is not the issue. We can imagine other ways of relying on others for our moral beliefs that raise all the same problems. ${ }^{14}$ For example, Danielle's friend might refuse to tell her what to believe about the war in Gaza, but Danielle might infer that she thinks the war is unjust by noting that her friend is planning to go to the demonstration. Or Danielle might

\footnotetext{
${ }^{10}$ See Mothersill (1984: 159-160).

${ }^{11}$ Robson (2012).

${ }^{12}$ Gorodeisky (2010), Hopkins (2001, 2011).

${ }^{13}$ Laetz (2008), Meskin (2004, 2006), Robson (2013).

${ }^{14}$ See Howell (2014: 394), McGrath (2011: 115).
} 
rely on sophisticated brain-scanning technology of the not-so-distant future to decode her friend's moral opinions. We can also imagine non-standards ways of getting others' moral beliefs into our heads. A common trope in cyberpunk fiction involves characters downloading information directly into the neocortex. We can imagine that Danielle asks her friend to input her moral beliefs into a computer that will implant the same beliefs in Danielle.

As these examples make clear, the acts of telling and listening are ultimately inessential to the problematic features associated with moral testimony. There's a more general problematic associated with relying on others to settle moral questions. Deferring to testimony is merely the standard case. Plausibly, a pessimist theory ought to be able to generalize straightforwardly to explain what's going wrong in the non-standard cases outlined above.

With these points on board, I think we have a good enough understanding of what pessimism commits us to. As stated, I'm assuming that pessimism provides the best fit for our intuitions. This isn't uncontroversial and controversy on this point isn't entirely due to misunderstanding. One prima facie plausible non-pessimist proposal holds that the inappropriateness of deferring in cases like Danielle's can be explained by the extent of moral disagreement pertaining to such controversial issues. ${ }^{15}$ We might think that the tendency of potential informants to disagree blocks reliance on testimony for any subjectmatter and doesn't point to any distinctive problem with moral testimony. Although superficially plausible, I think pessimists have exposed flaws in this proposal. For example, it's unclear why Danielle should trust that she can get the right answer by personal deliberation if the extent of disagreement is such that she can't trust her peers to have found the right answer. ${ }^{16}$

\footnotetext{
${ }^{15}$ Sliwa (2012: 186-8).

${ }^{16}$ Hopkins (2007: 620-1), Howell (2014: 395-6).
} 
Overall, I think pessimists have argued convincingly that their view accords with our intuitions. The question for us is why. What are the special normative considerations that govern reliance on testimony in ethics? In sections 3 and 4, I argue that pessimist theories currently on offer are subject to serious objections. This motivates the need for a new theory, which I put forward in section 5.

\section{The Value of Moral Understanding}

In this section, I'm going to argue against the most popular pessimist theory, according to which there are distinctive obstacles to relying on moral testimony because testimony fails to convey understanding, whereas understanding is uniquely important in the moral domain. Philip Nickel (2001) was the first to arrive at a view of this kind. The position is now more strongly identified with Alison Hills (2009, 2010), whose work is notable for integrating insights from recent work on understanding in the epistemology literature. ${ }^{17}$ Robert Hopkins (2007) and Sarah McGrath (2011) also favour this view as the most plausible articulation of moral testimony pessimism.

The idea that testimony fails to convey understanding appears plausible. If Danielle relies on her friend to tell her that Israel's war in unjust, she'll come to believe that the IDF is guilty of unjustifiable killings without understanding why these killings contravene the ethics of war. Danielle isn't able to grasp that the war is unjust based on an appreciation of its wrong-making features. She's similarly unable to understand why she ought to demonstrate against the war.

It's perhaps less obvious why moral understanding should be so valuable. The standard explanation appeals to the importance of understanding for morally worthy

${ }^{17}$ See Elgin (2006), Grimm (2006, 2014), Kvanvig (2003), Pritchard (2009), Riggs (2003), Zagzebski (2001). 
action. ${ }^{18}$ To be good, it's not enough to do the right thing, nor even to do the right thing because you know it to be right. Thus, there's something deficient about a person who rescues a child from drowning if she's moved exclusively or even primarily by the thought that this is her duty. She ought to be moved by concern for the life of the child. Plausibly, good people are motivated not only or primarily by the fact that a given action is right, but also by those features of the world which make actions right: e.g., the welfare and dignity of others. ${ }^{19}$ Thus, we might think, adequate appreciation of the right-making features of actions is necessary for morally worthy conduct. For our actions to be morally worthy, we therefore need moral understanding.

Although this view is plausible on its face, I believe it should be rejected. Its initial plausibility doesn't hold up on reflection and it is subject to serious objections.

Firstly, a little imagination puts a question-mark over the claim that understanding can't be conveyed by testimony. Danielle's friend might tell her not simply that the war is unjust but also why this is so, and Danielle might trust her on this point. In doing so, she doesn't seem to make her dependence on her friend's moral views any less problematic.

Noticing this problem, Hills $(2009,2010)$ argues that we should distinguish knowing why $p$ from understanding why $p$. The former can be conveyed by testimony in the way described above, but it's the latter that's necessary for morally worthy action. However, I will argue that Hills fails to provide an account of understanding on which someone could not acquire understanding by deference in a case like Danielle's.

\footnotetext{
${ }^{18}$ Some point to other valuable features of moral understanding. Thus, Hills (2010) and Nickel (2001) both argue that understanding is an especially reliable source of right action as it involves the ability to generalize across relevantly similar cases. As will become clear in discussion, it must be false that only understanding conveys this ability, unless understanding is also the sort of thing that can be conveyed by testimony.

19 Smith (1994: 75-76).
} 
According to Hills, understanding why $p$ is associated with a distinctive set of abilities that do not come with simply knowing why $p .{ }^{20}$ Hills favours the view that understanding is holistic rather than discrete: understanding pertains to networks of facts, not isolated bits of information. ${ }^{21}$ Whereas someone who knows why $p$ might know this and nothing more, Hills (2010) suggests that understanding is constituted by a set of abilities that allow one to go beyond the issue at hand: "To understand why p you must have an ability to draw conclusions about similar cases, and to work out when a different conclusion would hold if the reasons why p were no longer the case.” (194)

This proposal doesn't seem to me to identify a deficiency in moral testimony that can't be rectified by the addition of more testimony. Whereas the abilities outlined above might not be conferred by accepting an explanation for $p$ taken in isolation, it seems that some amount of additional testimony encompassing a broader range of issues should be sufficient. Danielle's friend might tell her not only why the current Gaza war is unjust but also why other wars have shared (or failed to share) its problematic features and how its moral status might have been different given differences in its objectives, expected civilian casualties, etc.

Hills (2010: 195-196) nonetheless insists that understanding cannot be conferred in this way. Understanding is constituted by a set of abilities, whereas testimony conveys propositional knowledge. Hills maintains that "no extra piece or pieces of knowledge guarantee that you have these abilities.” (196) This may be so, but it does not seem to answer the objection. Provided that Danielle already has a good working memory and a general ability to follow explanations and draw inferences, the extensive body of testimonial

\footnotetext{
${ }^{20}$ Drawing on Kvanvig (2003: 196-200), Hills also claims that understanding is distinct from knowledge in that the former isn't undermined by epistemic luck in the same way as the latter. I think Grimm (2006) has already shown decisively that Kvanvig's argument is flawed, so I won't discuss this point here.

${ }^{21}$ See Kvanvig (2003), Moravcsik (1979), Zagzebski (2000).
} 
knowledge described in the previous paragraph would seem sufficient to confer the particular abilities identified by Hills. Granted, Danielle must already have these general background abilities. In that sense, it's true that understanding cannot be conveyed merely by testimony. However, the required abilities seem to be ones that a normal and welleducated person would already have and may be assumed to have. For this reason, Hills does not appear to identify a genuine obstacle to acquiring moral understanding via deference in a case like Danielle's.

Sarah McGrath (2011: 136-137) suggests a different reply to the worry that moral understanding can be conferred by testimony if relevant explanatory information is also conveyed. Like Julius Moravcsik (1979) and Stephen Grimm (2006, 2014), McGrath suggests that there exists an important analogy between understanding and a priori insight. Consider the following. There seems to be a difference between knowing that a conclusion is entailed by a set of premises and being able to see the entailment relation. Imagine a mathematician who completes a large, multi-stage proof. Upon completing the proof, she knows that the conclusion follows from the premises, but she may not be able to see it as following in the way that she can see each step in the proof as following on from the previous. It's tempting to suppose that whoever understands a proof must also be able to see or grasp the links between the steps: it's not enough to simply know that each step follows. We might suppose that an analogous requirement governs understanding more generally: understanding requires not only knowing that certain relations of dependency exist, but seeing or grasping those connections.

In fact, appeals to metaphors of seeing and grasping are ubiquitous in the literature on understanding, though attempts to characterise these states rarely go beyond analogies like the one outlined above. ${ }^{22}$ Hills $(2009,2010)$ also appeals to the metaphor of grasping,

\footnotetext{
${ }^{22}$ See Grimm (2006, 2014), Kvanvig (2003), Moravcsik (1979), Riggs (2003), Strevens (2013), Zagzebski (1999).
} 
but she favours the view that there is nothing more to grasping explanatory dependencies than possession of the capacities for generalization described earlier. ${ }^{23}$ We might reasonably resist this view. Consider again the analogy with mathematical proof. Someone could have the ability to know when a given conclusion follows in a mathematical proof by having in her memory a giant look-up table: there might be no limit to the generality of her ability to test the validity of a proof using this method, and yet she might never be able to see any conclusion as following from a set of premises. ${ }^{24}$ Similarly, the ability to see relevant explanatory relationships may be thought of as something more than the mere ability to draw the right conclusions across a sufficiently wide range of relevantly similar cases.

On the current proposal, then, moral understanding requires not only knowing that an action is wrong because it has certain features, nor simply the ability to make inferences about its moral status based on information about its morally relevant properties, but also seeing or grasping the connection between its having those features and its being wrong. A view like this seems to represent a better reply to the objection that understanding can be achieved by relying on sufficiently large quantities of testimony. As we've seen, extensive knowledge about when one step in a mathematical proof follows from the previous can be had without the ability to see the links between them. Similarly, someone who is simply told that a certain action is wrong because it has certain features will not see the connection between those features and the wrongness and so will not understand why the action is wrong.

Significant questions remain about how to interpret the notion of seeing appealed to here. For example, we may wonder whether there are noticeable behavioural differences between seeing an explanatory connection and simply knowing it exists. If so, what are they? Alternately, we may ask whether these states are supposed to be able to be told apart

\footnotetext{
${ }^{23}$ Hills, personal communication.

${ }^{24}$ Cf. Block (1981).
} 
by introspection. If so, how? We might also wonder what relationship there is between this kind of seeing or grasping and the eureka experience that often accompanies understanding. Are they the same or different?

These questions aren't simply matters of curiosity. They point to a genuine problem. To avoid the objection that moral understanding can be conveyed by testimony, it seems plausible to suppose that understanding requires seeing or grasping relations of explanatory dependence. However, if the claim that morally worthy action requires understanding has to be interpreted using this rarefied sense of understanding, the intuitive plausibility of the claim is put in doubt. Under this proposal, someone might fail to understand why a given action is required despite knowing the action is obligatory, knowing why it's obligatory, and knowing how the moral status of the action would change across variations in its descriptive properties. If a person does the right thing guided by this rich body of moral knowledge, how convincing is it to suppose that her action lacks moral worth because she does not also see the relevant grounding relationships? Given our uncertainty about what exactly this state of seeing would involve, the conclusion seems less than compelling.

There are further problems facing the view that testimony is defective because it fails to convey understanding. For example, this view has trouble accommodating the intuition that agnosticism may be preferable to deference. In the example with which I began, Danielle is initially agnostic as to the morality of the war in Gaza. She recognizes that the IDF operation has certain problematic features, but she hasn't made up her mind. This seems okay. Things go wrong when Danielle comes to believe that the war in unjust based on her friend's say-so. Thus, there seems to be something inappropriate in the transition from agnosticism to deference. How are we to explain this in terms of the value of moral understanding? On the face of it, agnosticism is no better than deference when it 
comes to understanding why the war is wrong. Nonetheless, agnosticism seems appropriate, whereas deference does not. ${ }^{25}$

Here is one possible reply. We might suppose that if Danielle remains agnostic and refuses to rely on her friend, she's going to have to think through the problem on her own in a way that's likely to give rise to understanding. However, if she defers to her friend, she'll already have settled the issue: she's unlikely to give the question further consideration and therefore unlikely to acquire understanding. In this vein, Hills (2010) claims that trusting moral testimony "could make it less likely that your belief is grounded in the right way, hence make it less likely that you act well.” (220) Agnosticism may thus be better in terms of option value.

However, it seems easy to imagine cases where the likelihood that Danielle will come to understand the relevant moral considerations is independent of whether she chooses to defer or remain agnostic. For example, Danielle might be an undergraduate signed up for a class on war ethics that will use the recent Gaza conflict as a case study. She might be required to turn in a paper demonstrating deep and detailed consideration of the reasons for and against the justice of the war. In that case, whether she now chooses to believe her friend or reserve judgment may do nothing to decrease the likelihood that she'll come to understand why the war is wrong. Nonetheless, it seems appropriate for her to remain agnostic for the time being.

\footnotetext{
${ }_{25}$ We might suppose that in some cases the moral status of an action is genuinely indeterminate, such that agnosticism is the epistemic response required by an appreciation of the morally relevant features of the action. We may thus be able to explain the value of suspending judgment in terms of the value of understanding in a case like this. However, the value of agnosticism does not appear limited in this way. In Danielle's case, the immorality of the war may be assumed to be a determinate matter of fact. Furthermore, we should not think that Danielle's agnosticism represents a settled attitude toward the war's moral status, like the state of suspended judgment described by Friedman (2013). Rather, her agnosticism is the absence of any settled attitude.
} 
Here is a final problem, which I believe is the most serious. There are in fact many acceptable ways of forming moral beliefs that fail to convey understanding. There is nothing distinctive about moral testimony in that respect. More importantly, these other sources of moral knowledge do not appear to share the problematic status that we associate with moral testimony.

Consider moral intuition. Many moral claims are believed because they strike us as true. Intuitively, it's permissible to turn the trolley in Foot's original Trolley Case but wrong to push the man in front of the trolley in Thomson's Footbridge Case. Most people haven't any idea as to why the one action is permissible and the other isn't. ${ }^{26}$ Some philosophers claim to have an idea, but their explanations are devised post hoc. In many cases, their explanatory principles have little plausibility apart from their explanatory power.

In fact, inference to the best explanation poses the same problem. A philosopher might come to believe the Doctrine of Double Effect because it best explains our intuitions about trolley cases. Although she might now be better placed to understand why you can turn the trolley but not push the man, she might well come up blank if asked why the Doctrine of Double Effect is true. Even supposing she could offer some explanation, she couldn't go on ad infinitum. At some point, explanation must give out. There will be certain bedrock moral facts that simply have no deeper ground. A plausible candidate might be the fact that suffering is bad. Supposing this is a brute fact, it will be in principle impossible to understand why suffering is bad. It just is. Still, this doesn't seem to pose any especial problem for drawing conclusions about the badness of suffering.

Induction also seems to be an acceptable means of generating new moral beliefs without moral understanding. By inference from past behaviour, Holmes infers that Moriarty is doing something wrong at this very moment. Nonetheless, Moriarty's criminality may be so variegated that Holmes can't identify the particular wrong-making

${ }^{26}$ See Hauser et al. (2007). 
features of his current scheme. Nonetheless, this might be a perfectly acceptable bit of Holmesian "deduction".

As this shows, many perfectly acceptable ways of forming moral beliefs fail to convey understanding. The putative fact that moral testimony fails to convey understanding therefore seems a poor explanation for why we ought not to rely on testimony in cases like Danielle's. The proposal fails to identify a distinctively problematic feature of testimony as a source of moral belief.

This completes my case against the view that testimony is distinctively problematic in light of the special value placed on moral understanding. As we've seen, the initial plausibility of this position drains under scrutiny. In addition, the proposal faces serious problems. It can't explain why agnosticism may be appropriate in cases where deference is not. Most importantly, many perfectly acceptable sources of moral knowledge fail to convey understanding: the view fails to identify a potentially problematic feature particular to moral testimony.

\section{Aretaic Considerations}

In a recent paper, Robert Howell (2014) puts forward a novel suggestion as to why there are distinctive obstacles to relying on moral testimony. On his view, the problematic status of moral testimony is explained via considerations related to virtue and moral character. Although Howell gets a number of points right, I think his virtue-focused theory ultimately falters.

Drawing on familiar Aristotelian ideas, Howell assumes that the virtues are integrated suites of cognitive, conative, and active dispositions. The virtuous person not only knows the right thing to do, but reacts accordingly in terms of affect and behaviour. Thus, the brave person knows which dangers ought to be faced, exhibits appropriate levels of fear, and stands her ground when necessary. These reactions reflect the same underlying 
competence: namely, the virtue of courage. This idea of the virtues as coherent, integrated response-patterns will be important in Howell's theory. His account isn't otherwise distinctively Aristotelian and doesn't presuppose any controversial commitments of contemporary virtue ethics.

Howell's discussion of the relationship between deference and virtue is rich and multi-faceted. I'm going to focus on the core deficiency that he identifies in beliefs derived via moral testimony: namely, that they are likely to be isolated from the agent's character. Howell claims that we want to see a person's moral beliefs as "subjectively integrated" (411), finding "rich support within her own character." (411) Our moral beliefs are ideally incorporated within and reflective of the integrated response-patterns characteristic of the virtues, including relevant emotional and motivational dispositions. Beliefs acquired via testimony fall short on that account.

Although Howell recognizes a certain debt to pessimist views that emphasize the value of understanding, beliefs that fit this ideal of character needn't involve any such cognitive achievement. It's consistent with Howell's conception of virtue that a person's moral reactions might be immediate and unreflective, guided by intuitions or flashes of emotion without any appreciable ability to explain the grounds of her judgments.

I think Howell captures an important aspect of the problem. A person's moral beliefs seem to belong more closely to her identity than her beliefs about the geography of India or the mating habits of gentoo penguins. Therefore, it's promising to suppose that a key problem with testimonial beliefs is that they are somehow alien to the self. Nonetheless, I'll argue that aretaic considerations fail to provide the right theoretical framework within which to capture these important insights.

I want to point to two problems facing Howell's view. The first involves a restatement of an objection that I pressed against Hills. 
As we saw in reflecting on Danielle's case, agnosticism on moral questions may be preferable to deference even when deference involves the acquisition of true beliefs via a reliable source. Howell's view appears unable to explain how this could be so. Someone who lacks even a true belief about what she ought to do doesn't appear to do any better in terms of realizing an ideal of virtuous character. The person who defers at least has one element of the response-pattern that the virtuous person would exhibit: she knows the right thing to do. Nonetheless, agnosticism strikes us as acceptable in cases where deference does not. This suggests that the realization of virtue is not what's telling against relying on others in cases like Danielle's.

This gap in Howell's account may be less a matter of accident than design. Howell frames the issue as one of explaining why deference is dispreferable in comparison with gaining moral knowledge first hand. He says that his account "only maintains that one who has a belief by deference is less optimal (all things being equal) than one who gains the belief in a way that doesn't involve deference." (411) It might be unsurprising, then, that Howell's view can't explain why agnosticism is sometimes appropriate when relying on testimony isn't.

Here is a second and more serious objection. Howell emphasizes that testimonial beliefs are deficient because they are isolated from the agent's moral character and are unlikely to be well-integrated within the non-cognitive dispositions that partially constitute her character. He highlights the extent to which beliefs acquired via testimony are unlikely to carry with them the appropriate emotional responses and corresponding motivations. On reflection, this feature of moral testimony isn't really problematic. Quite the opposite. If accepting moral testimony did cause changes of this kind, it would only be more disturbing.

Imagine a guru whose words have hypnotic powers, altering not only a person's moral beliefs but also her character, including her affective dispositions. These hypnotic powers ensure that the beliefs the guru communicates carry with them the appropriate non- 
cognitive responses highlighted by Howell as lacking in testimonial beliefs. Contrary to what we should expect if Howell has identified the key problematic feature in beliefs of that kind, deferring in this case seems all the more disconcerting.

There is a potential reply to this problem. John Martin Fischer and Mark Ravizza (1998) suggest that virtues are historical phenomena: whether someone counts as brave or compassionate depends not simply on what they are like, but how they got to be that way. According to Fischer and Ravizza, certain dispositions count as virtues only if they arise through an appropriate process involving education and habituation. In light of this, they insist that "one cannot simply take a virtue pill and suddenly have the relevant virtue." (192) If we grant this, we might suppose that aretaic considerations can explain the problem with the guru's testimony. Although relying on her testimony might in some sense bring about the right character, the resulting state would fall short in light of its deviant aetiology.

I don't believe the virtues are historical in this sense. Certainly, I think we should reject the view that the virtues are essentially the product of a certain kind of upbringing described by Aristotle. Joshua Knobe and Brian Leiter (2007) argue that Aristotelian views about character development are empirically unsupported in light of evidence from behavioural genetics that personality differences are explained to a large extent by genetic differences and not by differences in upbringing. Even supposing that this turns out to be mistaken, we can note the following. Were it true, it would be far more natural to say that Aristotle had a mistaken theory about the aetiology of the virtues than that no one is virtuous according to Aristotle's theory. We should therefore reject the view that the virtues are defined by their aetiology.

In light of these problems, I believe that Howell's view ought to be rejected, though it gets a number of points right. The suggestion that moral testimony is problematic insofar as testimonial beliefs fail to find deep roots within the self puts us on the right track. However, the virtue-centred framework seems the wrong way to develop this proposal. As 
we've seen, this framework can't explain why agnosticism is sometimes preferable to learning the truth via deference. It also fails to accord with our intuitions in certain nonstandard cases where acceptance of moral testimony changes a person's character. In the next section, I'll try to sketch a better way forward. ${ }^{27}$

\section{The Demands of Authenticity}

In the remainder of this paper, I'm going to argue that our uneasiness with moral testimony can be explained by our attachment to an ideal of authenticity. I'll begin with some remarks about the status of this ideal, emphasizing my own ambivalence. I then show how moral testimony pessimism represents a natural upshot of the demands of authenticity. Finally, I point to a number of theoretical virtues distinctive of this proposal.

Each of us can no doubt easily set out a handful of platitudes about what it means to be authentic: it means being true to yourself, living in such a way that your actions and decisions express your innermost thoughts and feelings, and so on. It's correspondingly

${ }_{27}$ Recall that my aim is not to vindicate pessimism, but to explain why it appears plausible. In light of the issues I've raised, Howell could choose to present his view as revisionary, insisting that even if his theory doesn't capture our intuitions about moral deference, it's nonetheless correct as an account of how we ought to respond to moral testimony. He might even rely on my argument in this paper to dismiss conflicting intuitions as relying on a misguided attachment to authenticity as an ethical ideal. In this way he could insist that deferring to the guru is in fact not so problematic and also that there is no good reason for remaining temporarily agnostic in cases like Danielle's. Note that Hills could in principle try to reformulate her view in a similar fashion, insisting that our intuitions should be assigned little weight and that they ought to give way whenever they conflict with the implications of her theory. I'm not sure what Howell's paper or Hills's paper(s) would look like if re-drafted as purely top-down arguments made without appeal to case-based intuitions, nor how convincing they would be. Sadly, adequate treatment of this issue falls beyond the scope of this paper. The only thing we can be sure of is that the resulting views would depart significantly from our intuitions about the proper role of testimony in moral epistemology. I am grateful to an anonymous referee for raising this issue. 
difficult to make these platitudes precise and theoretically adequate. Where philosophers have tried, we find confusion rather than clarity. Established accounts of authenticity fall into two very different camps. ${ }^{28}$ We have a discovery model, on which a person's identity is something given, a voice within known through introspection and meditation. This model may be attributed to Rousseau (1762/1974). We also have a decision model, on which authenticity requires that each person determine her identity via the exercise of free choice. This model may be attributed to Sartre (1946/2007). These different models involve strikingly divergent conceptions of the true self, indicating that authenticity is an essentially contested concept.

Noting the climate of confusion surrounding the value of authenticity, Charles Taylor (1991) describes us as burdened with "an extraordinary inarticulacy about one of the constitutive ideals of modern culture." $(18)^{29}$ Readers hoping that I might break the spell will be disappointed. I'll make my case in the following drawing principally on our intuitive sense of what it means to be authentic, cashed out via familiar platitudes and metaphors whose imprecisions I'll leave unresolved. The need for greater precision is something I take to be a consequence of my argument, not a presupposition, for reasons I'll now explain.

Philosophers including Charles Taylor (1989, 1991) and Charles Guignon (2004) have portrayed authenticity as one of the constitutive ethical ideals of our culture. Nonetheless, I think the value of authenticity deserves to be put in question. In fact, we find clear grounds for skepticism in the authors just mentioned. Taylor sees our attachment to authenticity as partly responsible for the self-absorption and social atomism thought by many to characterise contemporary culture. ${ }^{30}$ Guignon argues that the received conception of authenticity has been put in question by our rejection of Romantic assumptions about

\footnotetext{
${ }^{28}$ See Bublitz \& Merkel (2009), Varga (2012).

${ }^{29}$ Cf. Knobe (2005).

${ }^{30}$ See, e.g., Putnam (2000).
} 
nature against the background of which this ideal of self-discovery originally made sense. ${ }^{31}$ Each portrays an ethic of authenticity as requiring substantial rehabilitation. ${ }^{32}$

Whether our implicit attachment to authenticity stands up to reflective scrutiny is, I believe, an open question. By arguing that our intuitions about moral testimony reflect our attachment to authenticity, I want to convince you that closing this question is necessary to deciding whether moral testimony pessimism ultimately holds up. Precisifying the ideal of authenticity will be a key sub-goal in closing this question, but not in the argument I want to make here.

With these points in mind, I'll now proceed to outline the demands of authenticity in such a way that deciding moral questions under one's own steam represents a natural upshot of these requirements. I'll then explain why I think we attach special value to authenticity in the moral domain, drawing on the idea that our moral outlook is an especially central part of our identity.

At the heart of our conception of authenticity is an ideal of harmony between the inner and outer facets of a person. The key assumption is that each of us has a set of beliefs, desires, tastes, and sentiments which go together to make up our true, inner self. The states that guide us in our day-to-day existence may or may not be the same. The key anxiety attached to the ideal of authenticity is that the social conditions of modern life conspire to bring the outer and the inner out of joint. Authenticity is achieved when the beliefs and motives that guide a person are expressive of her true self. Inauthenticity arises when these states fail to give expression to who we really are.

Assuming that authenticity is both possible and desirable, we appear to have a natural explanation for our reluctance to accept moral testimony. To be authentic, the beliefs which guide us through life must give expression to the true self. This seems to

\footnotetext{
${ }^{31}$ On which, see Taylor (1989: 355-390).

32 See also Varga (2012: 127-157).
} 
require that we should decide moral questions on our own terms, so far as we can, so that our own moral sensibility is manifest in the values and ideals by which we live. By contrast, relying on moral testimony puts us in a condition of inauthenticity, since the moral beliefs that guide us fail to give expression to the traits that make us who we are, deep down. ${ }^{33}$

This explanation appears sufficiently simple and straightforward that it's only natural to feel there must be something wrong with it. Here is one worry. The proposal may seem to suffer from an element of vacuity. Suppose we accept that authenticity requires that the beliefs which guide us give expression to the self and this explains why there are special obstacles to relying on moral testimony. We might worry that we've gained little explanatory insight unless we can also say why moral beliefs are special in this regard. Why does authenticity make special demands of our moral beliefs? Why isn't our authenticity similarly at stake when it comes to beliefs about geography or zoology? It might seem that this question is ultimately a restatement of the basic question of why there are special obstacles to relying on moral testimony.

This concern about vacuity can be met, I believe. As I noted earlier, it's natural to assume that a person's moral beliefs are especially central to her identity. We are defined by our values and ideals. Similarly, the characteristic symptom of an 'identity crisis' is a loss of ethical knowledge: a sense of deep confusion about what matters and makes life worthwhile. ${ }^{34}$

This view is supported by recent empirical research on folk ideas about identity. Nina Strohminger and Shaun Nichols (2014) report the results of five experiments designed to test what they call Essential Moral Self Hypothesis, according to which a person's moral traits are the most essential part of her identity. The experiments asked participants to consider vignettes describing realistic and unrealistic changes that a person might undergo

\footnotetext{
${ }^{33}$ For similar descriptions of moral authenticity see Feinberg (1983: 36-37) and Taylor (1991: 25-26). ${ }^{34}$ See Taylor (1989: 25-52).
} 
and to report which traits they expected to endure or otherwise result in loss of identity. Thus, subjects were asked to imagine meeting a friend after twenty-five years and consider which changes in this person would most alter her true self. Subjects' responses confirmed the hypothesis, treating their friend's moral traits as most central to her identity. Similar results were found across the board. Strohminger and Nichols conclude that a person's identity is defined by her moral sensibility.

If we take this conclusion at face value, we have a natural explanation for why authenticity makes especial demands on our moral beliefs. Our authenticity is especially at stake when it comes to the makeup of our moral outlook because our moral traits are especially central to our identity.

Let me note two limitations of this proposal. From the perspective of the results reported by Strohminger and Nichols, it involves a certain degree of extrapolation. Their surveys asked participants to assess the significance of broad dispositions, not specific beliefs. Thus, when respondents were asked to identify those changes that would most alter their friend's identity, the moral traits they had to consider included racism and honesty, but not specific beliefs, such as opposition to the death penalty or belief in the fairness of free markets. All the same, the assumption that beliefs of this kind have a similar intimacy with respect to the self seems very natural.

The second limitation of the explanation proposed here is that it may appear somewhat shallow unless we have a further explanation for why our moral traits are so central to identity. I don't believe we have a good explanation for that fact. ${ }^{35}$ I also don't

35 For some off-the-cuff suggestions, see Strohminger \& Nichols (2014: 168-169), Taylor (1989: 28-29). Strohminger \& Nichols appeal to considerations related to the evolution of cooperation, but these seem to me to be considerations of the wrong kind; as Taylor notes, the notion of identity in play here is a historically contingent characteristic of modernity. Unfortunately, I do not understand Taylor's own suggested explanation. Very roughly, he suggests that moral orientation is fundamental to identity because we define our identity in terms of how we answer for ourselves. 
believe it's necessary at this point. Every explanation is incomplete to some extent. Whether these omissions constitute defects depends on our aims. The view that morality and identity are intimately linked explains why authenticity places especial demands on our moral beliefs. That's all I'm trying to show here. A deeper understanding of the link between morality and identity is desirable, not obligatory.

I'll now outline some distinctive benefits of my approach. As the reader will have noticed, my view is similar to Howell's in important respects. ${ }^{36}$ Many of the complaints he lodges against beliefs derived from testimony are at home within my view: in particular, the complaint that beliefs of this kind are not subjectively integrated and fail to find rich support within a person's character. We part company in explaining why this is a bad way for moral beliefs to be. He appeals to virtue; I appeal to authenticity. I'll now show that appealing to authenticity instead of virtue allows us to avoid both of the objections that I levelled against Howell in the previous section. In addition, it allows us to explain straightforwardly why aesthetic testimony shares the problematic features associated with moral testimony.

Let's begin by returning to the issue of agnosticism. As I argued, there seems to be nothing in the nature of virtue to give preference to agnosticism over true belief. If anything, true belief would appear to be a step in the right direction, however short of the final aim. Nonetheless, our intuition is that agnosticism is less problematic in Danielle's case.

If we understand the appeal of moral testimony pessimism as grounded in the value of authenticity, we can explain this quite straightforwardly. Authenticity and inauthenticity are contraries, not contradictories. Thus, you can be neither authentic nor inauthentic. Heidegger (1927/2008) describes human existence as having the potential "for authenticity or for inauthenticity or for a mode in which neither of these has been differentiated." (275)

${ }_{36}$ This is no coincidence: my own thinking has been shaped very much by Howell's paper. 
When the moral beliefs that guide us give expression to our moral sensibility, we achieve authenticity. When the moral beliefs that guide us fail to be expressive in this way, we are to that extent inauthentic. In conditions where we remain agnostic, we're neither one nor the other. Plausibly, this undifferentiated mode is less valuable than authenticity, but not as bad as inauthenticity. For this reason, agnosticism may be preferable to deference in the moral domain.

Another objection that I made against Howell's account is that he can't explain why it seems so disturbing to accept testimony from the guru described at the end of section 4 . The guru's words change a person's character alongside her beliefs, ensuring that she acquires the appropriate emotional responses and corresponding motivations: in that respect, her beliefs are subjectively integrated. However, this seems even worse than ordinary cases of moral testimony.

Again, my account offers a satisfying explanation. It's natural to suppose that our authenticity is threatened if others make deep changes in our psychology, bypassing our critical faculties. This seems especially true if they introduce new values and commitments. This point is emphasized in a number of compatibilist responses to the problem of manipulation. Both Alfred Mele (1995) and Ishtiyaque Haji (1998) argue that manipulated agents can't be held responsible because they act from inauthentic evaluative schemes. Thus, Haji says: "her action is not 'truly her own' as it issues from an evaluative scheme that is not 'truly her own'; her engineered-in-scheme is unathentic [sic.].” (108) To address the problem of manipulation, Haji and Mele attempt to set out necessary and sufficient historical conditions for authenticity to supplement more familiar compatibilist criteria for appraisability. ${ }^{37}$ More generally, authenticity seems a very plausible candidate for a historical phenomenon. This impression is reinforced by the prevalence of accounts that

\footnotetext{
${ }^{37}$ See also Haji \& Cuypers (2008) and Mele (2006).
} 
understand authenticity in terms of narrative unity in life. ${ }^{38}$ For this reason, my view is well-placed to explain the peculiarly disturbing quality of the guru example.

Here's a final advantage distinctive to my view. As I noted in section 2, aesthetic testimony seems to share many of the problematic features of moral testimony. Plausibly, it's not a desideratum on a pessimist theory that it can be transposed to explain the problematic status of aesthetic testimony. Nonetheless, theories with greater explanatory power are pro tanto preferable.

If we explain the problematic status of moral testimony by appeal to considerations of virtue and good character, our theory seems necessarily limited to the case of moral testimony. We may be able to say that beliefs derived from aesthetic testimony are also problematic because they do not stem from the agent and lack subjective integration. ${ }^{39}$ However, the importance of this appears difficult to understand if subjective integration is valued for the sake of realising an Aristotelian ideal of virtue.

By contrast, an explanation in terms of authenticity can be generalized with ease. The aesthetic has often been seen as a key arena in which to succeed or fail in realizing one's authenticity..$^{40}$ The ideal of authenticity has been described as evolving in concert with those important changes in Western aesthetic understanding occurring around the turn of the nineteenth century that emphasize sentiment and subjective resonance as central to aesthetic appreciation. ${ }^{41}$ As heirs to this cultural shift, we naturally feel that the aesthetic judgments we formulate and communicate should express our own sensibility. They should convey how we genuinely feel about the object, how it resonates with us. Thus, Rilke (1929/2011) refuses to judge the merits of the young poet's verse for him, insisting: "There

\footnotetext{
${ }^{38}$ See Guignon (2004: 65-74), Varga (2012: 81-83).

${ }^{39}$ Howell (2014: 404, 410).

${ }^{40}$ Guignon (2004: 75-76), Taylor (1991: 61-65, 82-89).

${ }^{41}$ Taylor (1989: 368-390).
} 
is only one way. Go into yourself." (6) Unlike the ideal of virtue, the ideal of authenticity is sufficiently broad to encompass both moral and aesthetic testimony.

This completes my case for the view that the value of authenticity explains the perceived existence of special obstacles to relying on others for our moral beliefs. As I've shown, moral testimony pessimism represents a natural upshot of the demands of authenticity. Furthermore, we can explain why this ideal makes special demands on our moral beliefs as opposed to beliefs about geography or biology. The view has a number of distinctive plus points. It can account for the value of agnosticism. It can explain why deference looks worse in cases where Howell's view predicts it should look better. Finally, it can straightforwardly explain the problematic features associated with aesthetic testimony. I think we should accept this view.

\section{Conclusion}

There seem to be distinctive obstacles to relying on moral testimony in cases like Danielle's. I've argued that these obstacles can't be explained in terms of the value of moral understanding, nor in terms of aretaic considerations related to subjective integration. To explain why we're so reluctant to rely on moral testimony, we have to appeal to the perceived importance of authenticity.

I'm unsure to what extent authenticity represents an ideal to which we should aspire. I don't know whether it's possible to identify a true self whose expression ought to be valued. Even philosophers who are confident that authenticity is of value insist that it needs rehabilitation, severing its associations with self-absorption and outmoded beliefs

about human nature. Whether our attachment to authenticity stands up to scrutiny is an 
open question. Closing this question is necessary to deciding whether the view for which I've argued vindicates pessimism or casts it into doubt. ${ }^{42} 43$

\section{References}

Aiken, Henry David (1962) Reason and conduct: new bearings in moral philosophy. New York, NY: Knopf.

Block, Ned (1981) Psychologism and behaviourism. Philosophical Review 90(1), 5-43.

Bublitz, Jan Cristoph \& Merkel, Reinhard (2009) Autonomy and authenticity of enhanced personality traits. Bioethics 23(6), 360-374.

Crisp, Roger (2014) Moral testimony pessimism: a defence. Aristotelian Society Supplementary Volume 88(1), 129-143.

Elgin, Catherine (2006) From knowledge to understanding. In Stephen Hetherington, ed. Epistemology Futures, 199-215. Oxford: Oxford University Press.

Enoch, David (2014) A defense of moral deference. Journal of Philosophy 111(5), 229-258.

${ }^{42}$ Suppose you've found my argument convincing so far. On reflection, you too are unsure of the value of authenticity. However, you find that your intuitions about Danielle's case and others like it are still in place. This might be taken to suggest that my view has failed to explain what really underlies these intuitions. If I'm right, shouldn't our sense that something is wrong with moral testimony recede if we find the value of authenticity uncertain on reflection? (I'm grateful to an anonymous referee for this objection.) I don't believe this implication holds. It's not true, generally speaking, that accepting a debunking explanation for some normative intuition results in the loss of that intuition. Consider a person raised by religious fundamentalists who later rejects her upbringing and embraces secular humanism. She might well continue to experience an automatic feeling of moral disapproval whenever she meets a gay couple, in spite of acknowledging and explicitly repudiating the source of these intuitions. Such is the power of enculturation. Readers of this paper have most likely been raised in a culture in which the value of authenticity is deeply ingrained. It's therefore to be expected that we'll continue to feel an intuitive sense of disapproval at deference to moral testimony even if we explicitly reject authenticity as an ethical ideal.

${ }^{43}$ For helpful comments on previous drafts of this paper, I'm grateful to Alison Hills, Robert Howell, and an anonymous referee at this journal. 
Estlund, David M. (2008) Democratic authority: a philosophical framework. Princeton, NJ: Princeton University Press.

Driver, Julia (2006) Autonomy and the asymmetry problem for moral expertise. Philosophical Studies 128(3), 619-644.

Feinberg, Joel (1983) The moral limits of the criminal law, volume 3: harm to self. Oxford: Oxford University Press.

Fischer, John Martin \& Ravizza, Mark (1998) Responsibility and control: a theory of moral responsibility. Cambridge: Cambridge University Press.

Friedman, Jane (2013) Suspended judgment. Philosophical Studies 162(2), 165-181.

Gorodeisky, Keren (2010) A new look at Kant's view of aesthetic testimony. British Journal of Aesthetics 50(1), 53-70.

Grimm, Stephen R. (2006) Is understanding a species of knowledge? British Journal for the Philosophy of Science 57(3), 515-535.

(2014) Understanding as knowledge of causes. In Abrol Fairweather, ed. Virtue epistemology naturalized: bridges between virtue epistemology and philosophy of science, 329-345. Springer: Dordrecht.

Groll, Daniel \& Decker, Jason (2014) Moral testimony: one of these things is just like the others. Analytic Philosophy 55(1), 54-74.

Guignon, Charles (2004) On being authentic. London: Routledge.

Haji, Ishtiyaque (1998) Moral appraisability: puzzles, proposals, and perplexities. Oxford: Oxford University Press.

Haji, Ishtiyaque \& Cuypers, Stefaan E. (2008) Moral responsibility, authenticity, and education. London: Routledge.

Hare, R. M. (1963) Freedom and reason. Oxford: Oxford University Press.

Hauser, Marc, Fiery Cushman, Liane Young, R. Kang-Xing Jin, \& John Mikhail (2007) A dissociation between moral judgments and justifications. Mind \& Language 22(1), 1-21.

Heidegger, Martin (1927/2008) Being and time, transl. John Macquarrie \& Edward Robinson. New York, NY: Harper \& Row. 
Hills, Alison (2009) Moral testimony and moral epistemology. Ethics 120(1), 94-127.

(2010) The beloved self: morality and the challenge from egoism. Oxford: Oxford University Press.

Hopkins, Robert (2001) Kant, quasi-realism, and the autonomy of aesthetic judgment. European Journal of Philosophy 9(2), 166-189.

(2007) What is wrong with moral testimony? Philosophy \& Phenomenological Research 74(3), 611 634.

(2011) How to be a pessimist about aesthetic testimony. Journal of Philosophy 108(3), 138-157.

Howell, Robert (2014) Google morals, virtue, and the asymmetry of deference. Nous 48(3), 389-415.

Knobe, Joshua (2005) Ordinary ethical reasoning and the ideal of 'being yourself. Philosophical Psychology 18(3), 327-340.

Knobe, Joshua \& Leiter, Brian (2007) The case for Nietzschean moral psychology. In Brian Leiter \& Neil Sinhababu, eds. Nietzche and morality, 83-109. Oxford: Oxford University Press.

Kvanvig, Jonathan L. (2003) The value of knowledge and the pursuit of understanding. Cambridge: Cambridge University Press.

Laetz, Brian (2008) A modest defence of aesthetic testimony. The Journal of Aesthetics and Art Criticism 66(4), 355-363.

Lillehammer, Hallvard (2014) Moral testimony, moral virtue, and the value of autonomy. Aristotelian Society Supplementary Volume 88(1), 111-127.

McGrath, Sarah (2009) The puzzle of pure moral deference. Philosophical Perspectives 23(1), 321-344. (2011) Skepticism about moral expertise as a puzzle for moral realism. Journal of Philosophy 108(3), $111-137$.

McMahan, Jeff (2014) Gaza: is Israel fighting a just war? Prospect. Online article: <http://www.prospectmagazine.co.uk/philosophy/gaza-is-israel-and-hamass-conflict-a-justwar $>$

Mele, Alfred R. (1995) Autonomous agents: from self-control to autonomy. Oxford: Oxford University Press.

(2006) Free will and luck. Oxford: Oxford University Press. 
Meskin, Aaron (2004) Aesthetic testimony: what can we learn from others about beauty and art? Philosophy \&ं Phenomenological Research 69(1), 65-91.

(2006) Solving the puzzle of aesthetic testimony. In Matthew Kieran \& Dominic McIver Lopes, eds. Knowing art: essays in aesthetics and epistemology, 109-124. Dordrecht: Springer.

Moravcsik, Julius (1979) Understanding and knowledge in Plato's philosophy. Neue Hefte fur Philosophie 15/16, 53-69.

Mothersill, Mary (1984) Beauty restored. Oxford: Oxford University Press.

Nickel, Philip (2001) Moral testimony and its authority. Ethical Theory and Moral Practice 4(3), 253266.

Pritchard, Duncan (2009) Knowledge, understanding and epistemic value. Royal Institute of Philosophy Supplement 64, 19-43.

Putnam, Robert D. (2000) Bowling alone: the collapse and revival of American community. New York, NY: Simon \& Schuster.

Rilke, Rainer Maria (1929/2011) Letters to a young poet, transl. Louth. London: Penguin

Riggs, Wayne D. (2003) Understanding 'virtue' and the virtue of understanding. In Michael DePaul \& Linda Zagzebski, eds. Intellectual virtue: perspectives from ethics and epistemology, 203-227. Oxford: Oxford University Press.

Robson, Jon (2012) Aesthetic testimony. Philosophy Compass 7(1), 1-10.

(2013) Aesthetic testimony and the norms of belief formation. European Journal of Philosophy online preprint.

Rousseau, Jean-Jacques (1762/1974) Emile, transl. Barbara Foxley. London: Dent

Sartre, Jean-Paul (1946/2007) Existentialism is a humanism, transl. Carol Macomber. New Haven, CA: Yale University Press.

Sliwa, Paulina (2012) In defense of moral testimony. Philosophical Studies 158(2), 175-195.

Smith, Michael (1994) The moral problem. Oxford: Blackwell.

Strevens, Michael (2013) No understanding without explanation. Studies in History and Philosophy of Science A 44(3), 510-515.

Strohminger, Nina \& Nichols, Shaun (2014) The essential moral self. Cognition 131(1), 159-171. 
Taylor, Charles (1989) Sources of the self: the making of the modern identity. Cambridge: Cambridge University Press.

(1991) The ethics of authenticity. Cambridge, MA: Harvard University Press.

Varga, Somogy (2012) Authenticity as an ethical ideal. London: Routledge.

Wolff, Robert Paul (1970) In defense of anarchism. New York, NY: Harper \& Row.

Zagzebski, Linda (2001) Recovering understanding. In Matthias Steup, ed. Knowledge, truth, and duty: essays on epistemic justification, responsibility, and virtue, 235-251. Oxford: Oxford University Press. 